\title{
Protein-Based Films Cross-Linked with 1-Ethyl-3-(3-dimethylamino-propyl) carbodiimide hydrochloride (EDC): Effects of the Cross-Linker and Film Composition on the Permeation Rate of $\boldsymbol{p}$-Hydroxyacetanilide as a Model Drug
}

\author{
Cláudia M. Z. Cristiano, Samira J. Fayad, Ledilege C. Porto and Valdir Soldi* \\ Grupo de Estudos em Materiais Poliméricos (POLIMAT), Departamento de Química, \\ Universidade Federal de Santa Catarina, 88040-900 Florianópolis-SC, Brazil
}

\begin{abstract}
Filmes reticulados de gelatina (Gel), caseína (Cas) e a mistura Gel/Cas $(1: 1, \mathrm{~m} / \mathrm{m})$ foram estudados em termos das propriedades térmicas, morfológicas e absorção de água e quanto ao perfil de permeação de $p$-hidroxiacetanilida ( $p$-HAA ) como fármaco modelo. O grau de reticulação por 1-etil-3-(3-cloridrato) dimetilaminopropil carbodiimida (EDC) foi de 90,6\% para filmes de Gel e cerca de $70 \%$ para filmes de Cas e misturas Gel/Cas $(1: 1, \mathrm{~m} / \mathrm{m})$. A total solubilidade dos filmes não-reticulados foi reduzida para somente 21 - 22\% após reticulação com EDC. Apesar do alto grau de reticulação, o intumescimento dos filmes de Gel $(87,2 \%)$ foi praticamente o dobro do determinado para filmes de Gel/Cas $(1: 1, \mathrm{~m} / \mathrm{m})$ e Cas. A taxa de permeação de $p$-HAA seguiu a ordem $\mathrm{Gel}>\mathrm{Gel} / \mathrm{Cas} \cong \mathrm{Cas}$ para filmes reticulados, ou seja, um comportamento consistente com o maior intumescimento da Gel em relação aos outros dois sistemas estudados. Os menores valores de permeação observados para filmes de Cas e Gel/Cas, sugerem que estes sistemas podem ser utilizados para controlar a permeação de fármacos. Considerando os diferentes modelos matemáticos aplicados, os sistemas estudados não mostraram um bom ajuste relativamente a equação de primeira ordem e somente uma parcial correlação com as equações de ordem zero e do modelo de Higuchi. No entanto, uma boa correlação $\left(r^{2}>0,99\right)$ foi obtida utilizando a equação da lei das potências (valores de $\mathrm{n}=0,70$ - 0,87), indicando que a permeação de $p$-HAA através dos filmes foi controlada principalmente pelo mecanismo de difusão.
\end{abstract}

Cross-linked films of gelatin (Gel), casein (Cas) and their $(1: 1, \mathrm{~m} / \mathrm{m})$ mixture (Gel/Cas) were studied in terms of their thermal, morphological and water absorption properties and the permeation profile of $p$-hydroxyacetanilide ( $p$-HAA) as a model drug. The degrees of cross-linking by 1-ethyl3-(3-dimethylaminopropyl) carbodiimide hydrochloride (EDC) were $90.6 \%$ for Gel films and approximately $70 \%$ for Cas and Gel/Cas films. The totally soluble non cross-linked films achieved only $21-22 \%$ of solubility after cross-linking with EDC. Despite the high cross-linking degree, the swelling of Gel films (87.2\%) was practically twice that determined for Gel/Cas and Cas films. The permeation rate of $p$-HAA followed the order $\mathrm{Gel}>\mathrm{Gel} / \mathrm{Cas} \cong$ Cas for cross-linked films, which is consistent with the Gel film showing a greater swelling than the other two systems studied. Lower permeation rates were observed for Cas and Gel/Cas films, suggesting that these could be used as rate-controlling systems for drug permeation. For the different mathematical models applied, the systems studied did not show a good fit with the first-order equation and only a partial fit with the zero-order equation and Higuchi's model. However, good correlations $\left(r^{2}>0.99\right)$ were obtained using the power law equation $(\mathrm{n}=0.70-0.87$ ), indicating that the $p$-HAA permeation through the films was mainly controlled by a diffusion mechanism.

Keywords: gelatin, casein, films, cross-linking, drug permeation

\section{Introduction}

Gelatin (Gel), which is obtained by partial degradation of collagen, has been extensively studied due to its

\footnotetext{
*e-mail: vsoldi@qmc.ufsc.br
}

abundance, biodegradability, relatively low cost and filmogenic properties..$^{1-5}$ The main application of gelatin in recent decades has been in the food and pharmaceutical industries. More recently, its use was extended to the biomedical field, mainly in hard and soft capsules, wound dressings and absorbent pads for surgical uses. ${ }^{6}$ 
Casein (Cas) is a milk-based protein which can form stable colloidal particles (micelles) and films due to its open secondary structure. ${ }^{7-9}$ The secondary structure is apparently associated with the high content of proline which disrupts the $\alpha$-helices and $\beta$-sheets, inducing, as a consequence, an open and flexible conformation of casein, facilitating film formation through intermolecular hydrogen bonding, electrostatic bonds and hydrophobic interactions. ${ }^{10}$ Four main casein fractions $\left(\alpha_{\mathrm{s} 1}, \alpha_{\mathrm{s} 2}, \beta, \kappa\right)$ are found in bovine milk, representing approximately 44 , 13,33 and $10 \%$ of casein, respectively. ${ }^{11}$ Considering their nutritional qualities, casein colloidal particles are mainly used for food applications, while casein films can be used for the protection of food products. ${ }^{10}$

Gelatin has been preferentially mixed with polysaccharides for different technological applications, and this approach has been extensively studied in terms of the effect of plasticizers and cross-linkers on the film properties. ${ }^{4,12-14}$ An alternative approach to modify protein film properties is to use cross-linkers such as transglutaminase (TGase) and 1-ethyl-3-(3-dimethylaminopropyl) carbodiimide hydrochloride (EDC). EDC has the advantages of not being incorporated into the structure of the protein and not being toxic in comparison with cross-linkers such as formaldehyde and glutaraldehyde. ${ }^{15}$ Chambi and Grosso evaluated the mechanical properties, morphology and water vapor permeability of gelatin and casein films cross-linked with TGase. ${ }^{16} \mathrm{~A}$ synergistic effect on the Cas/Gel film properties, mainly in a 75:25 $(\mathrm{m} / \mathrm{m})$ formulation, was observed by the authors. The water barrier properties of fish gelatin/chitosan films were studied by Kołodziejska and Piotrowska and they were not found to be affected by cross-linking with TGase or EDC. ${ }^{13}$ The effectiveness of the cross-linking of gelatin/ chitosan films with EDC was compared to the reaction using TGase. Modifications of fish gelatin and chitosan with TGase allowed films with a low solubility in aqueous medium. ${ }^{17}$ Gelatin/chitosan films have also been cross-linked with EDC and plasticized with glycerol. The presence of glycerol changed the mechanical properties and did not increase the water vapor permeability. ${ }^{13}$

The model drug used in this study ( $p$-hydroxyacetanilide) is an analgesic and antipyretic drug. ${ }^{18}$ In general, $p$-hydroxyacetanilide is effective with ingested doses ranging between $0.5-1.0 \mathrm{~g}$ every 3 or $4 \mathrm{~h}$. Considering that this causes inconvenience to the patient, many polymeric systems have been tested as new ways to control the release of different drugs. ${ }^{19-24}$ Investigations have been carried out in order to obtain an ideal model for drug delivery with high specificity and activity without toxic effects. ${ }^{25}$ Along with several drug delivery systems using membrane-controlled diffusion, films and membranes for transdermal delivery have also been studied. ${ }^{26-28}$ In this context, drug delivery systems using gelatin have received considerably more attention than those using casein. For example, gelatin/ alginate films cross-linked with calcium were used to study ciprofloxacin hydrochloride release. The authors suggested that the drug release increased with the gelatin content in the film due to pore formation. ${ }^{21}$ Gelatin and chondroitin sulfate hydrogels cross-linked with EDC and $N$-hydroxysuccinimide had been evaluated in systems for the controlled delivery of two proteins. ${ }^{23}$ In hydrogels based on chitosan/gelatin cross-linked with glutaraldehyde, the release of levamisole, cimetidine and chloramphenicol was evaluated. ${ }^{24}$ In the case of casein, microspheres cross-linked with glutaraldehyde have been used for progesterone release. ${ }^{20}$

In this study, our particular interest was to analyze the permeation rate of $p$-hydroxyacetanilide (a model drug) through gelatin/caseins films cross-linked with 1-ethyl3-(3-dimethylaminopropyl) carbodiimide hydrochloride (EDC). The permeation behavior was evaluated considering the thermal, mechanical, morphologic, and water absorption properties of the cross-linked system. The addition of casein and the treatment with the cross-linker (EDC) were carried out because it is known that gelatin films do not have the ideal water vapor barrier and water absorption properties for many of the applications in the food and pharmaceutical industries. ${ }^{14,29-31}$ In the context of the application of this system as films which allow $p$-hydroxyacetanilide permeation, parameters such as swelling, water absorption, water vapor permeability and film morphology are of particular importance.

\section{Experimental}

\section{Materials}

Gelatin type-B from bovine skin (225 Bloom) and 1-ethyl-3-(3-dimethylaminopropyl) carbodiimide hydrochloride (I) were purchased from Sigma-Aldrich. Casein and $p$-hydroxyacetanilide (II) was purchased from Acros Organics and a local market, respectively. Sodium chloride and sodium sulfate used to control the relative humidity (RH) over saturated salt solution (75 and 94\% $\mathrm{RH}$, respectively) and sodium hydroxide used to adjust the $\mathrm{pH}$ of the polymeric solutions were acquired from Nuclear. Monosodium phosphate monohydrate (Synth),

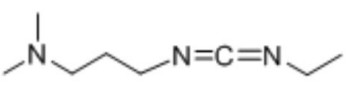

(l)

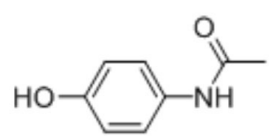

(II) 
disodium phosphate heptahydrate (Reagen Quimibrás), sodium chloride and potassium chloride (Nuclear) were used to prepare the buffer solutions.

\section{Film preparation}

Gelatin solution $(3 \%, \mathrm{~m} / \mathrm{v})$ was prepared in distilled and deionized water under magnetic stirring for $20 \mathrm{~min}$ at room temperature and for a further $40 \mathrm{~min}$ at $55 \pm 5^{\circ} \mathrm{C}$. A casein suspension $(3 \%, \mathrm{~m} / \mathrm{v})$ was prepared in distilled and deionized water under magnetic stirring for $30 \mathrm{~min}$ at room temperature and for a further $270 \mathrm{~min}$ at $90 \pm 5^{\circ} \mathrm{C}$. The $\mathrm{pH}$ of the casein solutions was adjusted to 9.0 with the addition of $\mathrm{NaOH}\left(4 \mathrm{~mol} \mathrm{~L}^{-1}\right)$ before film preparation. Films of gelatin (Gel), casein (Cas) and $1: 1(\mathrm{~m} / \mathrm{m})$ gelatin/ casein (Gel/Cas) were prepared. For the Gel/Cas film, equal amounts of both polymeric solutions were mixed and maintained at $55 \pm 5{ }^{\circ} \mathrm{C}$ for $25 \mathrm{~min}$. For the cross-linking treatment, EDC $\left(40 \mathrm{mmol} \mathrm{L}^{-1}\right)$ was added to the polymeric solutions and maintained under magnetic stirring for $1 \mathrm{~min}$ at room temperature. The resulting solutions were spread over polystyrene dishes and the film formed by casting at room temperature $(60 \pm 5 \% \mathrm{RH})$ during $48 \mathrm{~h}$. The films were dried under vacuum for $24 \mathrm{~h}$ (room temperature) and stored in a desiccator until analysis. The thickness of the films were in the range $0.10-0.13 \mathrm{~mm}$. The cross-linking degree of the Gel, Cas and Gel/Cas films was determined through the reaction of 2,4,6-trinitrobenzene sulfonic acid (TNBS) with the primary amine groups of the proteins according to the absorption spectroscopy method described by Bubnis and Ofner. ${ }^{32}$ The solution absorbance was measured at $346 \mathrm{~nm}$ using a Perkin Elmer spectrometer (Lambda 11/Bio).

\section{Thermomechanical analysis}

The glass transition temperature $\left(\mathrm{T}_{\mathrm{g}}\right)$ was determined by thermomechanical analysis using a Shimadzu TMA-50 analyzer. The samples were heated at a rate of $20^{\circ} \mathrm{C} \mathrm{min}^{-1}$, from $25^{\circ} \mathrm{C}$ to $120^{\circ} \mathrm{C}$ to remove the adsorbed water on film (holding the samples at this temperature for $10 \mathrm{~min}$ ). After cooling at room temperature, the samples were reheated at $10{ }^{\circ} \mathrm{C} \min ^{-1}$ to $250{ }^{\circ} \mathrm{C}$. Both heating events were carried

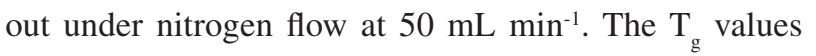
corresponded to the temperature at which the extrapolated curves converged. The analysis was carried out in triplicate.

\section{Scanning electron microscopy (SEM)}

The films were observed under a Philips XL30 scanning electron microscope. The cross-sections (fractured in liquid
$\mathrm{N}_{2}$ ) were fixed in a metal support and metallized with a fine gold layer.

\section{Solubility and swelling measurement}

Before the solubility or swelling measurements, the Gel/Cas films (2 cm x $2 \mathrm{~cm}$ ) were previously dry under vacuum until constant weight. To determine the solubility or swelling degree (SD) the crosslinked films were immersed in $30 \mathrm{~mL}$ of distilled and deionized water. The films were kept in water for $24 \mathrm{~h}$ to verify their solubility and were subsequently dried under vacuum until constant mass. For the SD measurements, the samples were removed from the water, dried with absorbent paper and weighed. The solubility and the SD were determined according to equation 1 , where

$\% X=\frac{\left(W_{t}-W_{o}\right) \times 100}{W_{o}}$

$X$ is the solubility or the $\mathrm{SD} ; W_{t}$ is the mass of the sample in time $t$ and $W_{o}$ is the mass of the dry sample. Measurements were performed in triplicate.

\section{Water vapor permeability}

Water vapor permeability (WVP) of the films was determined through the gravimetric method described in the ASTM E-96-00. ${ }^{33}$ This method is based on the increase in weight of silica gel placed inside a Teflon ${ }^{\circledR}$ capsule. This system was placed in a desiccator with $75 \pm 3 \%$ relative humidity at $24 \pm 2{ }^{\circ} \mathrm{C}$ for 3 days. All the films were dried in a vacuum oven for 5 days before the experiments. The slope of the linear plot between the weight loss and time was used to calculate the WVP. Each system was measured in triplicate.

\section{Mechanical properties}

Nine centimeter-length film samples were prepared. Tensile tests were performed at $25^{\circ} \mathrm{C}$ using an EMIC DL 2000 analyzer (EMIC, Brazil), according to the ASTM D882-95a for thin films. The films were kept at a relative humidity (RH) of $94 \pm 3 \%$ prior to analysis. Tensile strength at rupture, elongation and modulus of elasticity (Young's modulus) were determined from the stress-strain curves considering at least eight analyses of each sample.

\section{In vitro permeation studies and kinetic models}

The $p$-hydroxyacetanilide calibration curve was obtained through absorbance measurements of the drug 
solution $\left(0.02 \mathrm{mg} \mathrm{mL}^{-1}-0.00125 \mathrm{mg} \mathrm{mL}^{-1}\right)$ at $244 \mathrm{~nm}$ in a Perkin Elmer spectrometer (Lambda 11/Bio).

The $p$-hydroxyacetanilide permeation experiments were carried out in a diffusion cell at $37 \pm 1{ }^{\circ} \mathrm{C}$ with horizontal shaking. The cell consists of two compartments (donor and receptor) with $7 \mathrm{~mL}$ volume each side and a diffusion area of $6.8 \mathrm{~cm}^{2}$. The cross-linked films $(0.10-$ $0.13 \mathrm{~mm}$ thickness) were first kept in phosphate buffer ( $\mathrm{pH} 7.4$ ) for $1 \mathrm{~h}$ at $37 \pm 1{ }^{\circ} \mathrm{C}$ and later sandwiched between the two compartments. Phosphate buffer was used as the receptor side and phosphate buffer saturated with the drug (20.4 $\left.\mathrm{mg} \mathrm{mL}^{-1}\right)$ was used as the donor side. After pre-determined time intervals, samples $(0.2 \mathrm{~mL})$ were collected at the receptor side, diluted to $25 \mathrm{~mL}$ and the UV-Vis absorption analyzed at $244 \mathrm{~nm}$ Perkin Elmer spectrometer (Lambda 11/Bio). After each analysis, the total volume of the receptor side was replaced with new phosphate buffer to avoid sink conditions. The measurements were carried out in triplicate.

The diffusion process is based on Fick's first Law (equation 2), where $Q_{t}$ is the cumulative amount of drug which permeated through a certain surface area of membrane (obtained through the calibration curve), $P$ is the coefficient of permeability, $C_{D}$ and $C_{R}$ are the drug concentrations in the donor (D) and receptor $(\mathrm{R})$ side, respectively, and $t$ is time. ${ }^{34}$

$Q_{t}=P\left(C_{D}-C_{R}\right) t$

Under sink conditions, equation 2 can be reduced to equation 3 . In this way, the permeability of the membrane (P) is obtained from the slope of the linear region of the plot of $Q_{t} v s t$.

$Q_{t}=P C t$

The diffusion coefficient $(D)$ is related to the overall flux $(J)$ of the drug through the cross-section area of the polymeric film (equation 4), where $m$ is the amount of drug permeated through the film, $S$ is the cross-section area, $t$ is the time, $\mathrm{c}$ is the concentration and $\mathrm{x}$ is the film (barrier) thickness. The negative sign on the right side of the equation 4 means that the diffusion occurs in the opposite direction to the increase of concentration. This model has limitations and can only be applied when the diffusion coefficient is independent of concentration. ${ }^{35}$

$\frac{d m}{S . d t}=J=-D\left(\frac{d c}{d x}\right)$

Four different equations were selected in order to analyze the release profiles of the model drug:
$Q_{t}=Q_{\infty}-k_{0} t$

$\operatorname{Ln} Q_{t}=\operatorname{Ln} Q_{\infty}-k_{1} t$

$Q_{t}=k_{h} t^{1 / 2}$

$Q_{t}=k t^{n}$

where $Q_{t}$ and $Q_{\infty}$ are the amount of drug released at time $t$ and the drug load, respectively; $k_{0}, k_{1}, k_{h}$ and $k$ are the kinetic constants associated with the drug/polymer system and $n$ is the release exponent which is associated with the drug release mechanism and the shape of the polymeric matrix. $Q_{t} / Q_{\infty}$ values lower than 0.6 were used for all the kinetic models evaluated.

The zero order kinetics model (equation 5) is based on the slow release of drugs from non-dissociated pharmaceutical forms. ${ }^{36}$ On the other hand, if the release of the drug follows an exponential (first-order kinetics, equation 6), the mechanism is generally due to the diffusion of the drug from the polymer matrix to the environment and to the erosion of the polymer matrix.$^{37}$ Another proposed model is based on the Higuchi's equation (equation 7), ${ }^{38}$ in which the mechanism of the release is associated with the Fick's law and is dependent on the square root of time. Finally, the power law model (equation 8) is used to describe the mechanism of release associated to the combination of diffusion and Case II processes, which corresponds to Fickian and non-Fickian transport mechanisms, respectively. ${ }^{39}$

\section{Results and Discussion}

\section{Characterization of the cross-linked films}

To investigate the permeation of $p$-hydroxyacetanilide (a model drug) through the Gel, Cas and Gel/Cas films, the first part of this study involved the determination of different film parameters: cross-linking degree, solubility, swelling, water vapour permeability and mechanical properties.

The cross-linking degree in the films was evaluated through the reaction of 2,4,6-trinitrobenzene sulfonic acid (TNBS) with the free $\varepsilon$-amino groups (primary groups) of the proteins forming amide bonds. ${ }^{32}$ As observed in Table 1 , the cross-linking degrees in the pure Gel and Cas films were $90.6 \%$ and $69.6 \%$, respectively.

For the Gel/Cas film the percentage of cross-linking was $71.8 \%$, which is very close to the value for the pure Cas film. The presence of Cas in the films decreased the percentage of cross-linking because less $\varepsilon$-amino groups 
Table 1. Cross-linking degree, solubility and water absorption for the three studied systems

\begin{tabular}{lcccc}
\hline Film & $\begin{array}{c}\text { Cross-linking } \\
\text { degree }(\%)\end{array}$ & $\begin{array}{c}\text { Solubility } \\
(\%)\end{array}$ & $\begin{array}{c}\text { Swelling } \\
(\%)\end{array}$ & WVP $^{(1)}$ \\
\hline Gel & $90.6 \pm 2.2$ & $21.7 \pm 0.2$ & $87.2 \pm 8.3$ & $1.54 \pm 0.22$ \\
Gel/Cas & $71.8 \pm 2.1$ & $21.2 \pm 5.7$ & $41.8 \pm 6.1$ & $1.38 \pm 0.03$ \\
Cas & $69.6 \pm 3.0$ & $21.9 \pm 2.3$ & $32.5 \pm 4.2$ & $1.49 \pm 0.08$ \\
\hline
\end{tabular}

${ }^{(1)}$ Water Vapor Permeability x $10^{10}\left(\mathrm{~g} \mathrm{~s}^{-1} \mathrm{~m}^{-1} \mathrm{~Pa}^{-1}\right)$ determined only at $24 \pm 2{ }^{\circ} \mathrm{C}$.

are available in the protein chain. In fact, the cross-linking with EDC (carboxylic groups) for both proteins (Gel and Cas) occurs through a reaction with the free $\varepsilon$-amino groups present in the structure. In the case of gelatin, the reaction occurs between EDC and the free $\varepsilon$-amino groups of the lysine, hydroxylysine, aspartic and glutamic acid residues. According to the literature, ${ }^{40} \mathrm{Gel}$ has approximately 33 $\varepsilon$-amino and 120 carboxylic groups in a chain with a thousand aminoacids, which explains the higher degree of cross-linking. In particular, lysine residues appear in percentages of $2.8 \%$ in the Gel and $c a .2 .6 \%$ and $1 \%$ in the $\alpha_{\mathrm{S} 1}{ }^{-}$and $\alpha_{\mathrm{S} 2}$-casein, which are the most hydrophilic fractions, suggesting that the Cas cross-linking degree reflects, in part, in the structural differences between the two proteins.

Considering that the non-cross-linked films were totally soluble in water, the cross-linking efficiency for Gel, Cas and $\mathrm{Gel} / \mathrm{Cas}$ films were confirmed by the percentage of solubility in water. As observed in Table 1, the solubility of the cross-linked films was $c a .21 \%$, suggesting that the cross-linking process was efficient. Similar results have been reported for unmodified fish-skin gelatin films which are totally soluble in water at $25^{\circ} \mathrm{C}$. After cross-linking with transglutaminase (TGase) $\left(0.30 \mathrm{mg} \mathrm{mL}^{-1}\right)$ the solubility decreased to $27 \%$. At the same temperature and $\mathrm{pH} 6$, the solubility of fish-skin gelatin/chitosan films decreased from $65 \%$ (unmodified films) to $26 \%$ and $21 \%$ after cross-linking with TGase and EDC, respectively. ${ }^{13}$

The water absorption in the cross-linked polymeric films was evaluated considering the swelling degree (SD) and water vapor permeability (Table 1 ). The SD of the films remained practically constant in the range from 5 to $66 \mathrm{~h}$ of analysis. For this reason, Table 1 shows only the values determined following an immersion time of $24 \mathrm{~h}$.

The SD decreased with the casein content in the cross-linked films. As observed in Table 1 the swelling percentages were $87.2,41.8$ and $32.5 \%$ for $\mathrm{Gel}, \mathrm{Gel} / \mathrm{Cas}$ and Cas, respectively. Besides the high cross-linking degree of the Gel film (90.6\%), the high SD suggests the formation of a more hydrophilic structure in comparison to casein. One interesting point is the fact that the Cas film, which had the lowest cross-linking degree, had the lowest SD. At the same time, as was observed in relation to the crosslinking degree, the SD for the Gel/Cas film was close to that for the casein film, suggesting that Cas significantly affected the Gel structure. The fact that the Gel film had the highest cross-linking degree and SD indicates that the treatment with EDC favored the exposure of the free hydroxyl groups. This behavior seems reasonable if we consider that EDC reacted with the amine groups of Gel and not with the hydroxyl groups which are distributed along the protein chain. ${ }^{41}$ The Gel film cross-linked with $2.5 \%$ of glutaraldeyde showed a SD of $110 \% .^{42}$

No significant differences were observed in the water vapor permeability (WVP) values $\left(1.38-1.54 \times 10^{-10} \mathrm{~g} \mathrm{~s}^{-1} \mathrm{~m}^{-1} \mathrm{~Pa}^{-1}\right)$ for the three systems studied. These values were lower than those determined by Rivero et al. ${ }^{14}$ for gelatin films $\left(3.32 \times 10^{-10}\right.$ and $\left.5.16 \times 10^{-10} \mathrm{~g} \mathrm{~s}^{-1} \mathrm{~m}^{-1} \mathrm{~Pa}^{-1}\right)$ with thickness ranging between 210 and $410 \mu \mathrm{m}$, respectively. Also, Piotrowska et al. ${ }^{31}$ showed that the WVP $\left(7.33 \times 10^{-10} \mathrm{~g} \mathrm{~s}^{-1} \mathrm{~m}^{-1} \mathrm{~Pa}^{-1}\right)$ determined for unmodified fish-skin gelatin films were not significantly changed by cross-linking with TGase or EDC (6.89 and $6.61 \times 10^{-10} \mathrm{~g} \mathrm{~s}^{-1} \mathrm{~m}^{-1} \mathrm{~Pa}^{-1}$, respectively). These values are very close to those determined for fish-gelatin/ chitosan films under the same conditions a WVP value of $14.05 \times 10^{-10} \mathrm{~g} \mathrm{~s}^{-1} \mathrm{~m}^{-1} \mathrm{~Pa}^{-1}$ for casein/gelatin $(75 / 25, \mathrm{~m} / \mathrm{m})$ films cross-linked using TGase, which is approximately ten times higher than the values determined for similar systems in our study. According to the WVP values reported in the literature for similar systems and the parameters discussed above, the Gel, Gel/Cas and Cas films studied here seem to be appropriate for use as rate-controlling barriers for drug delivery systems.

\section{Glass transition temperature}

The glass transition temperatures $\left(\mathrm{T}_{\mathrm{g}}\right)$ for unmodified (in the absence of crosslinker) and cross-linked Gel, Cas and Gel/Cas films, are shown in Figure 1. For pure Gel and Cas the experimental $\mathrm{T}_{\mathrm{g}}$ values were 214.6 and $207.3{ }^{\circ} \mathrm{C}$, respectively. In the case of Gel, the $\mathrm{T}_{\mathrm{g}}$ was similar to the value of $212{ }^{\circ} \mathrm{C}$ determined by Bhaskar et al..$^{43}$ However, for pure Cas the $\mathrm{T}_{\mathrm{g}}$ value was higher than values reported in the literature $\left(144{ }^{\circ} \mathrm{C}\right) .{ }^{44}$ Unmodified $\mathrm{Gel} / \mathrm{Cas}$ mixtures showed only one $\mathrm{T}_{\mathrm{g}}$ value which lay between those for the pure components, indicating a certain miscibility. After cross-linking with EDC, the $\mathrm{T}_{\mathrm{g}}$ values for Gel and Cas decreased to 145.2 and $192.9^{\circ} \mathrm{C}$, respectively. The greater effect of EDC on the $\mathrm{T}_{\mathrm{g}}$ observed for Gel is in agreement with the cross-linking degree (90.6\%). As was observed for the unmodified mixtures, only one temperature was determined for cross-linked Gel/Cas mixtures, which was similar to that 


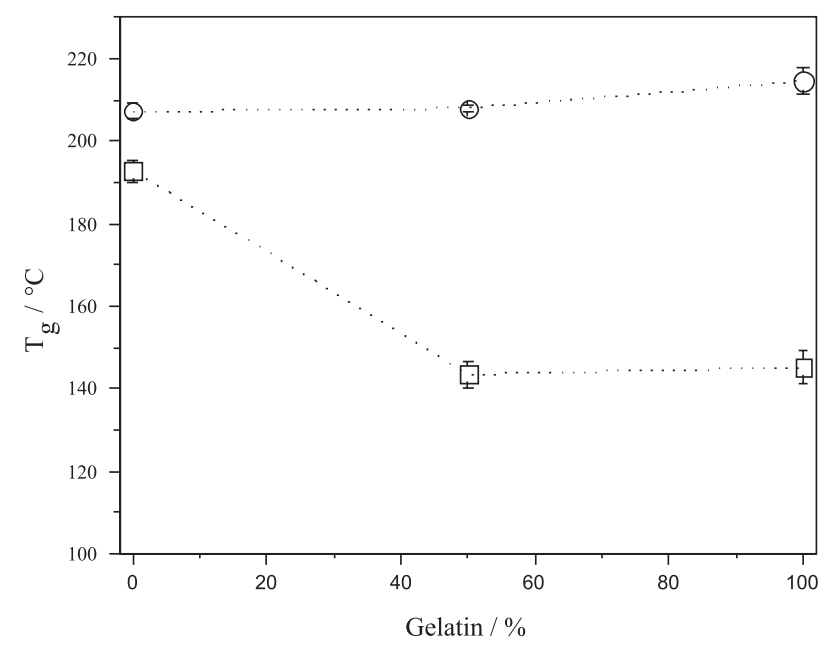

Figure 1. Glass transition temperatures for $(O)$ non cross-linked and $(\square)$ cross-linked films of Gel, Cas and Gel/Cas.

for cross-linked Gel $\left(\mathrm{ca} .140^{\circ} \mathrm{C}\right)$, suggesting that, in this case, the main factors affecting the $\mathrm{T}_{\mathrm{g}}$ were the high percentages of cross-linking and swelling of the Gel films. In general, a decrease in $\mathrm{T}_{\mathrm{g}}$ due to the presence of plasticizer agents is associated with an increase in the free volume between the polymeric chains, increasing their mobility, and decreasing, as a consequence, the intra- and intermolecular interactions between the protein chains. In the case of Gel and Cas, the cross-linking agent (EDC) had a similar effect, decreasing the $\mathrm{T}_{\mathrm{g}}$ to $c a .140{ }^{\circ} \mathrm{C}$. The partial miscibility (absence of strong interactions between the two proteins and EDC) appears to increase the mobility of the polymeric chains. This effect has been associated with the denaturation of the tertiary and quaternary structures in the proteins, decreasing the polymeric chain rigidity. Similar behavior was observed by Arvanitoyannis et al. ${ }^{3}$ for gelatin/starch mixtures.

\section{Scanning electron microscopy}

In Figure 2, the SEM micrographs of cross-sections of Gel, Cas and Gel/Cas films cross-linked with EDC are shown. In the absence of cross-linker (not showed) both films revealed a very smooth and dense matrix (surface and cross-section). In the presence of EDC the morphologic characteristics were quite different. The micrograph of the Gel film cross-section (Figure 2A) showed a high density, without porosity, and the matrix had lost its smoothness. Along with a high density, a greater roughness was observed for the Cas film cross-section (Figure 2C). The observed differences may be associated with the different behavior in terms of intermolecular interactions. The Cas films are characterized by a low intermolecular order and amphiphilic behavior, while gelatin is a fibrous protein with strong intermolecular interactions. These characteristics
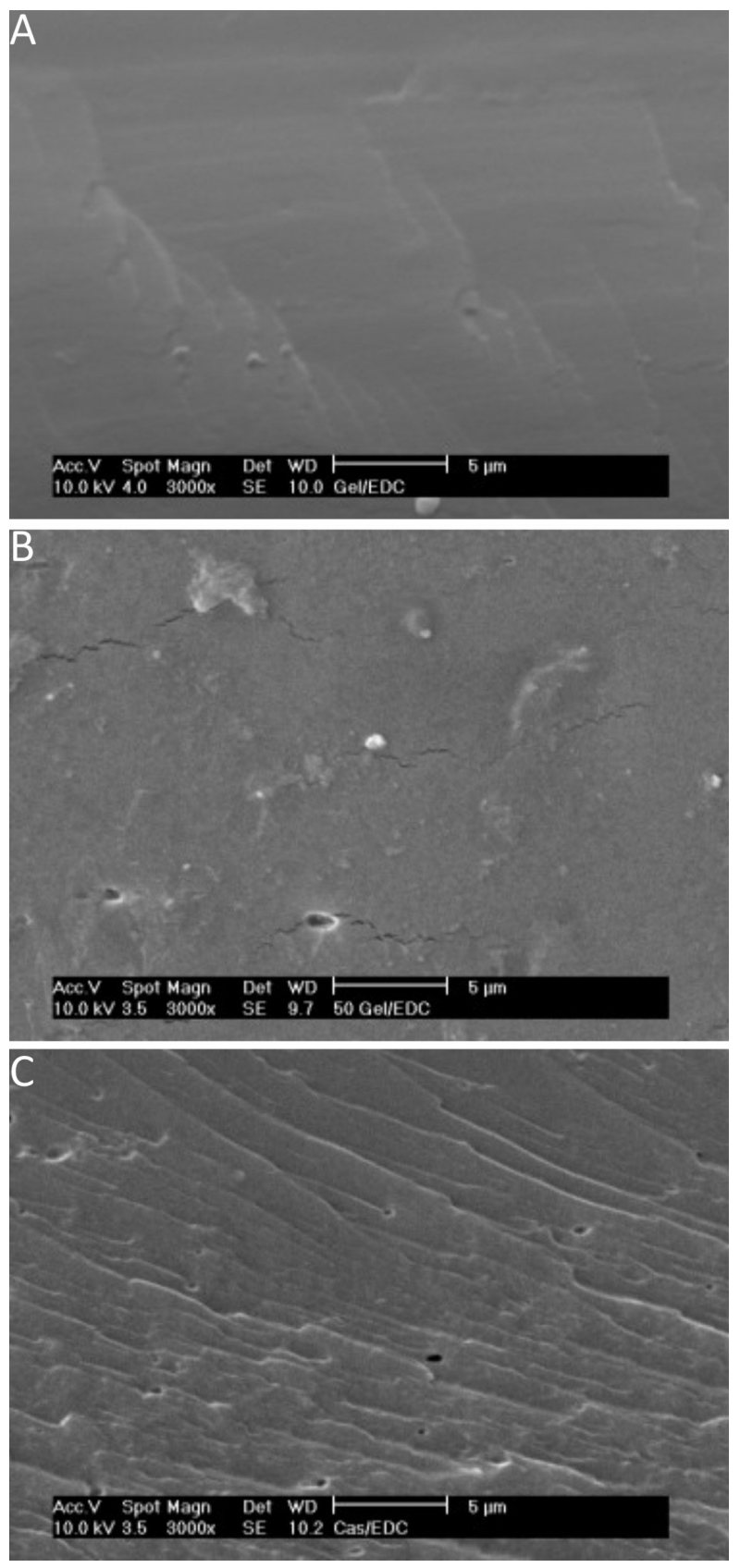

Figure 2. Cross-section micrographs for cross-linked films of: (A) Gel, (B) Gel/Cas, and (C) Cas.

may be associated with differences in terms of the main amino-acids present in the protein structures. The Gel/ Cas films (Figure 2B) appeared to have a more fragile structure (more similar to the Gel film) showing also a lower roughness in comparison to the Cas films.

\section{Mechanical properties}

Tensile testing provides information on the strength and elasticity of polymeric films or membranes. It is suggested that strong and flexible polymeric membranes 
Table 2. Mechanical parameters of gelatin/casein membranes at RH 94\%

\begin{tabular}{|c|c|c|c|c|c|c|}
\hline \multirow{2}{*}{$\begin{array}{l}\mathrm{Gel} / \mathrm{cas} \\
(\%, \mathrm{~m} / \mathrm{m})\end{array}$} & \multicolumn{3}{|c|}{ Uncrosslinked films } & \multicolumn{3}{|c|}{ Crosslinked films } \\
\hline & $\mathrm{TS}(\mathrm{MPa})$ & $\mathrm{E}(\%)$ & YM (MPa) & $\mathrm{TS}(\mathrm{MPa})$ & $\mathrm{E}(\%)$ & YM (MPa) \\
\hline $100 / 0$ & $33.3 \pm 2.5$ & $12.3 \pm 0.9$ & $298.1 \pm 21.6$ & $17.2 \pm 1.7$ & $15.0 \pm 1.9$ & $131.1 \pm 12.1$ \\
\hline $50 / 50$ & $50.5 \pm 1.7$ & $14.9 \pm 0.2$ & $176.2 \pm 13.6$ & $30.3 \pm 1.8$ & $21.3 \pm 1.8$ & $43.2 \pm 8.2$ \\
\hline $0 / 100$ & $10.1 \pm 0.0$ & $12.1 \pm 0.7$ & $181.1 \pm 10.1$ & $10.7 \pm 1.0$ & $39.1 \pm 7.5$ & $30.5 \pm 2.2$ \\
\hline
\end{tabular}

are particularly suited for applications such as transdermal therapeutic systems. ${ }^{28,45}$

The tensile strength (TS), elongation at break (E) and Young modulus (YM) for Gel, Cas and Gel/Cas systems determined at a relative humidity of $94 \%$ are shown in Table 2. The analysis of the values demonstrates a decrease of TS and $\mathrm{YM}$ and an increase in $\mathrm{E}$ with the cross-linking process (by EDC) for Gel, Cas (except for TS) and Gel/Cas systems. The TS values obtained for uncross-linked and cross-linked Gel/Cas films (50.5 and 30.3 MPa, respectively) were higher than those obtained for the pure proteins, suggesting a synergistic effect. In general, higher values of TS and YM would be expected with a cross-linking process. However, studies reported in the literature showed that gelation and casting processes of gelatin are able to recover part of the triple-helix structure of collagen (a more organized structure), resulting in a fibrous morphology. ${ }^{16}$ In our case, the cross-linking process contributed to the destabilization of the protein network, decreasing the intramolecular interactions between the polymers and, consequently, the resistance of the material. Uncross-linked Gel presented the highest value of YM (298.1 MPa), characterizing a more rigid structure. Apparently, the EDC has destroyed the $\alpha$-helix structure of gelatin, increasing the film flexibility (decrease of YM and increase of E). These results are in agreement with the $\mathrm{E}$ values reported by Chiellini et al. ${ }^{46}$ for Gel cross-linked with glutaraldeyde.

The mechanical parameters suggested that the crosslinking process increased the flexibility of the films which favor their application in systems such as transdermal delivery. The addition of Cas to the system also affected the Gel structure, contributing, as a consequence, to the increase in the flexibility of the films.

\section{In vitro permeation of $p-H A A$}

The permeation profiles of $p$-hydroxyacetanilide (model drug) in gelatin/casein cross-linked films in buffer solution pH 7.4 are shown in Figure 3. Both permeation profiles fitted very well $\left(\mathrm{r}^{2}>0.99\right)$ with a first-order exponential equation, indicating a good similarity in terms of the permeation mechanism (as discussed below). According to Figure 3, gelatin cross-linked films had a faster drug release, suggesting a direct dependence on the swelling degree $(87.2 \%)$. In general, a swollen matrix has larger spaces between the polymer chains, increasing, as a consequence, the permeation. The swelling measurements for the Gel/ Cas cross-linked films are reported elsewhere. In the Gel system, the $p$-HAA permeation equilibrium was reached after $10 \mathrm{~h}$. With the casein addition $(1: 1, \mathrm{~m} / \mathrm{m}, \mathrm{Gel} / \mathrm{Cas})$, the permeation rate of the drug through the polymeric membrane decreased, with equilibrium occurring only after $20 \mathrm{~h}$ of permeation. The values for the permeation rate or flux $\left(Q_{t} / t\right)$, determined from the slope of $Q_{t} v s t$ plots, are shown in Table 3. An increase in the gelatin percentage in the film from 50 to $100 \%$ increased the rate of permeation through the films (flux) from 8.9 to $15.6 \mathrm{mg} \mathrm{cm}^{-2} \mathrm{~h}^{-1}$. A similar behaviour was observed for the permeability and diffusion parameters. This result is to be expected, since the cross-linked gelatin film showed $87.2 \%$ of swelling while for casein this value was $32.5 \%$.

The results in Figure 3 and Table 3 also indicate that the drug permeation flux, permeability and diffusion coefficients in Gel/Cas films were similar to that of Cas, suggesting that Cas was able to modify the Gel properties.

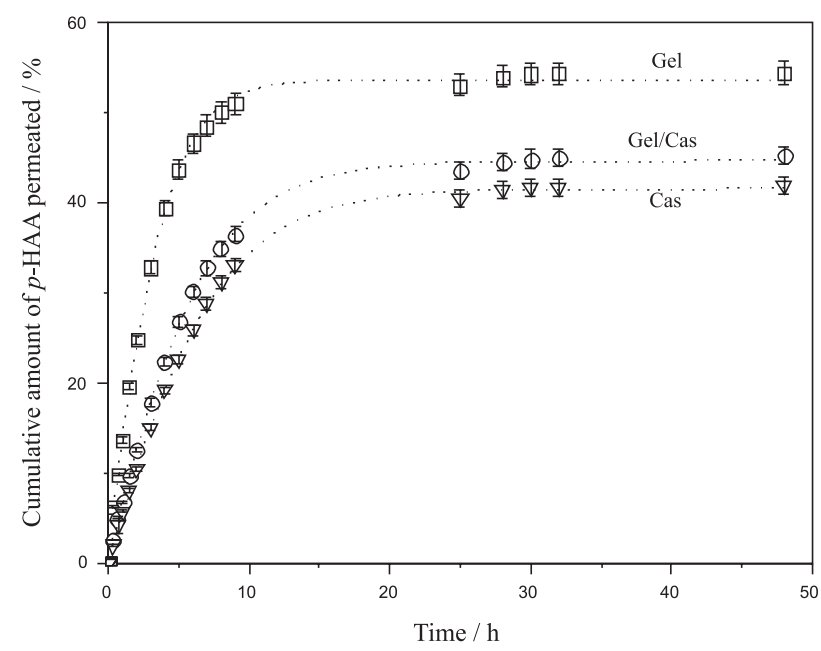

Figure 3. Permeation profiles of $p$-hydroxyacetanilide through: $(\square)$ Gel, (O) Gel/Cas, and $(\nabla)$ Cas films. Experiments carried out in buffer solution ( $\mathrm{pH} 7.4)$ at $37^{\circ} \mathrm{C}$.

The in vitro permeation profiles of Gel, Cas and Gel/ Cas were fitted according to zero- and first-order kinetics, 
Table 3. Release kinetics of Gel, Cas and Gel/Cas (1:1, m/m) films of $p$-hydroxyacetanilide considering the power law model (equation 8 ) and permeation parameters

\begin{tabular}{lcccccc}
\hline Films & $k\left(\mathrm{~h}^{-1}\right)$ & $n$ & $\mathrm{r}^{2}$ & Flux $^{(1)}$ & $\mathrm{P}^{(2)}$ & $D^{(3)}$ \\
\hline Gel & $22.65 \pm 1.03$ & 0.70 & 0.9953 & $15.6 \pm 0.3$ & $0.76 \pm 0.12$ & $3.24 \pm 0.23$ \\
Gel/Cas & $11.02 \pm 1.01$ & 0.84 & 0.9992 & $8.9 \pm 0.2$ & $0.44 \pm 0.14$ & $1.12 \pm 0.20$ \\
Cas & $9.12 \pm 1.02$ & 0.87 & 0.9988 & $7.6 \pm 0.2$ & $0.37 \pm 0.11$ & $0.86 \pm 0.16$ \\
\hline
\end{tabular}

(1)Flux $\left(\mu \mathrm{g} \mathrm{cm}{ }^{-2} \mathrm{~h}^{-1}\right) ;{ }^{(2)}$ Permeability coefficient $\left(\mathrm{cm} \mathrm{h}^{-1}\right) \times 10^{-3} ;{ }^{(3)}$ Diffusion coefficient $\left(\mathrm{cm}^{2} \mathrm{~h}^{-1}\right) \times 10^{7}$.

Table 4. Release kinetics of Gel, Cas and Gel/Cas films of $p$-hydroxyacetanilide

\begin{tabular}{|c|c|c|c|c|c|c|}
\hline \multirow[t]{2}{*}{ Films } & \multicolumn{2}{|c|}{ Zero-order } & \multicolumn{2}{|c|}{ First-order } & \multicolumn{2}{|c|}{ Higuchi } \\
\hline & $\mathrm{k}_{0}\left(\mathrm{~h}^{-1}\right)$ & $r^{2}$ & $\mathrm{k}_{1}\left(\mathrm{~h}^{-1}\right)$ & $r^{2}$ & $\mathrm{k}_{\mathrm{h}}\left(\mathrm{h}^{-1}\right)$ & $r^{2}$ \\
\hline Gel & $9.18 \pm 0.91$ & 0.9496 & $0.32 \pm 0.05$ & 0.9111 & $33.52 \pm 1.47$ & 0.9915 \\
\hline $\mathrm{Gel} / \mathrm{Cas}$ & $0.80 \pm 0.35$ & 0.9854 & $0.33 \pm 0.05$ & 0.9177 & $22.46 \pm 1.02$ & 0.9888 \\
\hline Cas & $6.10 \pm 0.24$ & 0.9915 & $0.30 \pm 0.04$ & 0.9111 & $20.00 \pm 1.00$ & 0.9866 \\
\hline
\end{tabular}

and the Higuchi's and power law models (Tables 3 and 4). The systems studied did not show a good fit with the first-order equation (equation 6), but values for the Cas $\left(r^{2}=0.9915\right)$ and Gel/Cas films did partially fit the zeroorder equation (Equation 5) $\left(\mathrm{r}^{2}=0.9854\right)$ (Table 4). In addition, for the Higuchi's model (equation 7) the fit for Gel was very good $\left(r^{2}=0.9915\right)$ and for Cas and Gel/Cas $\left(r^{2}>0.98\right)$ it was reasonable. However, a good correlation $\left(r^{2}>0.99\right)$ was obtained for all studied systems considering the power law model (equation 8, results in Table 3).

The slope $(n)$ values $(0.70 \leq n \geq 0.87)$ obtained using equation 8 indicated that a diffusion mechanism predominated in the $p$-HAA permeation in all the studied systems. Also, the kinetic constant $(k), p$-HAA flux, permeability and diffusion coefficients were almost the same for Cas and Gel/Cas films. However, following the tendency observed in terms of the swelling behavior, these values were around half those determined for Gel films.

\section{Conclusions}

The above investigations demonstrated that the rate of $p$-hydroxyacetanilide permeation followed the order $\mathrm{Gel}>\mathrm{Gel} / \mathrm{Cas} \cong \mathrm{Cas}$ for the cross-linked films. The faster drug permeation observed for the Gel film is in agreement with it having the greatest degree of swelling of the three systems studied. The presence of Cas in the $1: 1(\mathrm{~m} / \mathrm{m})$ mixture decreased the rate of the model drug permeation, suggesting that with appropriate mixtures of Gel and Cas it should be possible to produce rate-controlling systems for drug permeation. The permeation profiles for all systems studied fitted the power law model very well $\left(\mathrm{r}^{2}>0.99\right)$, with the $\mathrm{n}$ coefficient ranging from 0.70 to 0.87 , indicating that a diffusion mechanism predominated in the $p$-HAA permeation. In addition to the above characteristics, it was demonstrated through mechanical parameters that the flexibility of the Gel/Cas films increased with the crosslinking process and with the addition of casein, suggesting their application in systems such as transdermal delivery.

\section{Acknowledgements}

This research was supported by Conselho Nacional de Desenvolvimento Científico e Tecnológico (CNPq) and Universidade Federal de Santa Catarina (UFSC), Brazil.

\section{References}

1. Jongjareonrak, A.; Benjakul, S.; Visessanguan, W.; Prodpran, T.; Tanaka, M.; Food Hydrocolloids 2006, 20, 492.

2. Eastoe, J. E.; Leach, A.A.; The Science and Technology of Gelatin; Ward, A. G.; Courts, A., eds.; Academic Press: New York, 1997.

3. Arvanitoyannis, I.; Psomiadou, E.; Nakayama, S.; Aiba, S.; Yamamoto, N.; Food Chem. 1997, 60, 593.

4. Arvanitoyannis, I.; Kolokuris, I.; Nakayama, A.; Yamamoto, N.; Aiba, S.; Carbohydr. Polym. 1997, 36, 105.

5. Cao, N.; Fu, Y.; He, J.; Food Hydrocolloids 2007, 21, 1153.

6. Bigi, A.; Panzavolta, S.; Rubini, K.; Biomaterials 2004, 25, 5675.

7. Lucey, J. A.; Srinivasan, M.; Singh, H.; Munro, P. A.; J. Agric. Food Chem. 2000, 48, 1610.

8. Dauphas, S.; Mouhous-Riou, N.; Metro, B.; Mackie, A. R.; Wilde, P. J.; Anton, M.; Riaublanc, A.; Food Hydrocolloids 2005, 19, 387.

9. McHugh, T. H.; Krochta, J. M.; Food Technol. 1994, 48, 97.

10. Chen, H.; Protein-based films and coatings; Gennadions, A., ed.; CRC Press: London, 2002. 
11. Niño, M. R. R.; Sánchez, C. C.; Patino, J. M. R.; Colloids Surf., B 1999, 12, 161.

12. Arvanitoyannis, I. S.; Nakayama, A.; Aiba, S-I.; Carbohydr. Polym. 1998, 37, 371.

13. Kołodziejska, I.; Piotrowska, B.; Food Chem. 2007, 103, 295.

14. Rivero, S.; García, M. A.; Pinotti, A.; J. Food Eng. 2009, 90, 531.

15. Tomihata, K.; Burczak, K.; Shiraki, K.; Ikada, Y.; Polym. Biol. Biomed. Significance 1993, 24, 275.

16. Chambi, H.; Grosso, C.; Food Res. Int. 2006, 39, 458.

17. Kołodziejska, I.; Piotrowska, B.; Bulge, M.; Tylingo, R.; Carbohydr. Polym. 2006, 65, 404.

18. Miyazaki, S.; Kubo, W.; Itoh, K.; Konno, Y.; Fujiwara, M.; Dairaku, M.; Togashi, M.; Mikami, R.; Attwood, D.; Int. J. Pharm. 2005, 297, 38.

19. Grassi, M.; Voinovich, D.; Moneghini, M.; Franceschinis, E.; Perissutti, B.; Filipovic-Grcic, J.; J. Controlled Release 2003, 88,381 .

20. Latha, M. S.; Lal, A. V.; Kumary, T. V.; Sreekumar, R.; Jayakrishnan, A.; Contraception 2000, 61, 329.

21. Dong, Z.; Wang, Q.; Du, Y.; J. Membr. Sci. 2006, 280, 37.

22. Bonferoni, M. C.; Chetoni, P.; Giunchedi, P.; Rossi, S.; Ferrari, F.; Burgalassi, S.; Caramella, C.; Eur. J. Pharm. Biopharm. 2004, 57, 465 .

23. Kuijpers, A. J.; Van Wachem, P. B.; Van Luyn, M. J. A.; Brouwer, L. A.; Engbers, G. H. M.; Krijgsveld, J.; Zaat, S. A. J.; Dankert, J.; Feijen, J.; Biomaterials 2000, 21, 1763.

24. Yao, K. D.; Yin, Y. J.; Xu, M. X.; Wang, Y. F.; Polym. Int. 2003, $38,77$.

25. Sáez, V.; Hernáez, E.; Angulo, L. S.; Katime, I.; Rev. Iberoam. Polim. 2004, 5, 87.

26. Guy, R. H.; Pharm. Res. 1996, 13, 1765.

27. Kalia, Y. N.; Guy, R. H.; Adv. Drug Delivery Rev. 2001, 48, 159.

28. Kanis, L. A.; Generoso, M.; Meier, M. M.; Pires, A. T. N.; Soldi, V.; Eur. J. Pharm. Biopharm. 2005, 60, 383.
29. Arvanitoyannis, I.; Kolokuris, I.; Nakayama, A.; Yamamoto, N.; Aiba, S.; Carbohydr. Polym. 1997, 34, 9.

30. Cao, N.; Fu, Y.; He, J.; Food Hydrocolloids 2007, 21, 575.

31. Piotrowska, B.; Sztuka, K.; Kolodziejska, I.; Dobrosielska, E.; Food Hydrocolloids 2008, 22, 1362.

32. Bubnis, W. A.; Ofner III, C. M.; Anal. Biochem. 1992, 207, 129.

33. ASTM Standard E96-00, Standard Test Method for Water Vapor Transmission of Materials, Annual Book of ASTM Standard, 2000, 14.02:878-885.

34. Phuapradit, W.; Shan, N. H.; Williams, L.; Infeld, M. H.; Drug Dev. Ind. Pharm. 1995, 21, 955.

35. Martin, A.; Swarbrick, J. E.; Cammarata, A.; Physical Pharmacy, $4^{\text {th }}$ ed., Lippincott Williams \& Willians: Pensilvania, 1993.

36. Lopes, C. M.; Lobo, J. M. S.; Costa, P.; Rev. Bras. Cienc. Farm. 2005, 41, 143.

37. Shaffazick, S. R.; Guterres, S. S.; Freitas, L. L.; Pohlmann, A. R.; Quim. Nova 2003, 26, 726.

38. Higuchi, T.; J. Pharm. Sci. 1961, 50, 874.

39. Ritger, P.; Peppas, N. A.; J. Controlled Release 1987, 5, 37.

40. Veis, A.; The Macromolecular Chemistry of Gelatin, Academic Press: New York and London, 1964.

41. Livney, Y. D.; Schwan, A. L.; Dalgleish, D. G. J.; J. Dairy Sci. 2004, 87, 3638.

42. Bigi, A.; Cojazzi, G.; Panzavolta, S.; Rubini, K.; Roveri, N.; Biomaterials 2001, 22, 763.

43. Bhaskar. G.; Ford, J. L.; Hollingsbee, D. A.; Thermochim. Acta 1998, 322, 153.

44. Kalichevsky, M. T.; Blanchard, J. M. V.; Tokarczyk, P. F.; Int. J. Food Sci. Technol. 1993, 28, 139.

45. Khan, T. A.; Peh, K. K.; Ch'ng, H. S.; J. Pharm. Pharmaceut. Sci. 2000, 3, 303.

46. Chiellini, E.; Cinelli, P.; Fernandes, E. G.; Kenawy, E-R. S.; Lazzeri, A.; Biomacromolecules 2001, 2, 806.

Received: July 27, 2009 Web Release Date: November 26, 2009 